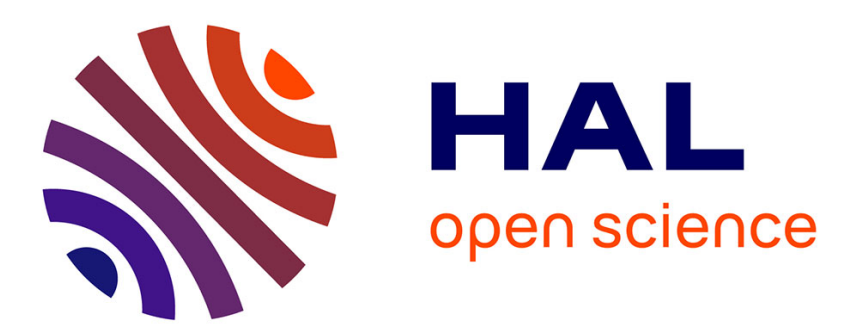

\title{
Diagnosis, assessment and repair of the Mathilde bridge close to collapse during a fire
}

Bruno Godart, Jacques Berthellemy, Jean Pierre Lucas

\section{To cite this version:}

Bruno Godart, Jacques Berthellemy, Jean Pierre Lucas. Diagnosis, assessment and repair of the Mathilde bridge close to collapse during a fire . Structural Engineering International, 2015, 25 (3), pp. 331-338. 10.2749/101686615X14210663188691 . hal-01215848

\section{HAL Id: hal-01215848 \\ https://hal.science/hal-01215848}

Submitted on 15 Oct 2015

HAL is a multi-disciplinary open access archive for the deposit and dissemination of scientific research documents, whether they are published or not. The documents may come from teaching and research institutions in France or abroad, or from public or private research centers.
L'archive ouverte pluridisciplinaire HAL, est destinée au dépôt et à la diffusion de documents scientifiques de niveau recherche, publiés ou non, émanant des établissements d'enseignement et de recherche français ou étrangers, des laboratoires publics ou privés. 


\section{Diagnosis, Assessment and Repair of the Mathilde Bridge Close to Collapse during a Fire}

Bruno F. Godart, Deputy Head Dept, Université Paris-Est, IFSTTAR, Marne La Vallée, France; Jacques Berthellemy, Director, Bridge Projects, CEREMA - Dtec ITM, Sourdun, France; Jean Pierre Lucas, Deputy General Director, Conseil Général de Seine Maritime - Pôle Aménagement et Mobilité, Rouen, France. Contact: bruno.godart@ifsttar.fr DOI: $10.2749 / 101686615 X 14210663188691$

\begin{abstract}
The Mathilde Bridge is one of the six bridges over the Seine River in the city of Rouen and supports a heavy traffic. It was built in 1977-1979 and is composed of a single steel span $115 \mathrm{~m}$ long, consisting of an orthotropic deck resting on two girders. On 29 October 2012, there was a major fire accident involving the Mathilde Bridge and it was immediately closed to traffic. After recalling the events, the article describes the emergency decisions that had to be taken, and then the extended diagnosis and the choice of the assessment method. Rapid decisions had to be taken regarding the waterway traffic under the bridge and the choice between repair or reconstruction.

The diagnosis consisted of a detailed inspection including the search for cracks and the condition of the paint, extensive non-destructive specific investigations carried out on the bridge and laboratory investigations on a few samples of steel. The assessment consisted of an accurate measurement of the global deformations of the entire span, a recalculation of the stability of the burned areas, and an expert analysis of the damaged support bearings. The article is written in the spirit of a forensic engineering approach.
\end{abstract}

Keywords: steel bridge; fire; emergency; diagnosis; assessment; investigations; recalculation; stability; repair; decision.

\section{Introduction}

The city of Rouen (100 000 inhabitgnts) is in the heart of an urban agglomeration of 450000 inhabitants and is organized around a bend of the Seine River. The Mathilde Bridge is one of the six bridges crossing the Seine River.

The Rouen agglomeration having no ring road, the Mathilde Bridge plays a strategic role in the flow of traffic in the city. Before the fire, it supported more than 80000 vehicles per working day, with nearly $20 \%$ of transit traffic. Moreover, it supported a sewage pipe serving the north of the city, and an optical fiber network.

The Mathilde Bridge was built between 1977 and 1979 and was designed by Setra (Services d'Etudes sur les Routes, les Transports et leurs Aménagements, now Cerema) in 1976. ${ }^{1}$ It has, in particular, two twin 115 m long steel spans; each span consists of an orthotropic deck resting on two girders that are $4 \mathrm{~m}$ high, $17.35 \mathrm{~m}$ apart and braced at every $4 \mathrm{~m}^{2}$ Each steel span rests at one end on an abutment and at the other end on the extremity of a cantilever, which is part of a continuous prestressed concrete boxgirder bridge passing over the Lacroix Island (see Fig. 1). The cross section of the Mathilde Bridge is shown in Fig. 2.

The bridge that was damaged in the fire is very similar to the Wiehl valley viaduct near Cologne in Germany that was also damaged in a similar fire in August 2004. ${ }^{3}$ However, the damages to the Mathilde Bridge were more extensive.

On 29 October 2012, a tanker truck carrying more than $20000 \mathrm{~L}$ of oil and gas caught fire on the Mathilde Bridge, by overturning in an access curve to the bridge. Its load spread over the whole width of the deck of the south steel span, then flowed toward the edges and ends of the bridge and set fire to other trucks that were parked under one end of the bridge. The steel span was subjected to two heavy fires localized in the vicinity of its abutment and to warm fumes propagating under the span (Fig. 3). The firefighters responded very quickly, avoiding a full collapse of the deck. They could use only water during the first phase of their intervention, and this prevented the temperature of the bridge from increasing to very high levels. They took at least $2 \mathrm{~h}$ to control and extinguish the two fires.

Fortunately, the driver of the tanker truck managed to escape and nobody was killed in the fire. Only two persons were slightly injured. The bridge was immediately closed to traffic, and the river navigation under the bridge was also stopped. This decision led to the displacement of some of the boatmen on the Northern pass usually reserved for recreational activities and to the stopping of the yacht club activities. These decisions were taken by the Prefect and the President of the Departmental Authority, given the uncertain condition of the bridge.

According to the fire department, the temperature of the fire was estimated to have reached between 650 and $800^{\circ} \mathrm{C}$. This estimate was based on experience from similar fires.

\section{The Management of the Crisis}

On 30 October, a specialized consultant was commissioned to make a first

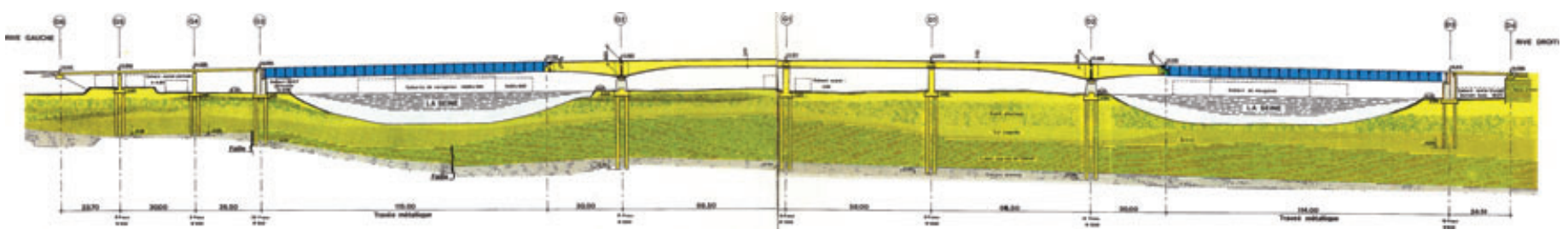

Fig. 1: Longitudinal elevation of the Mathilde Bridge (the steel spans are in blue and the prestressed concrete parts in yellow) (Units: $m$ ) 


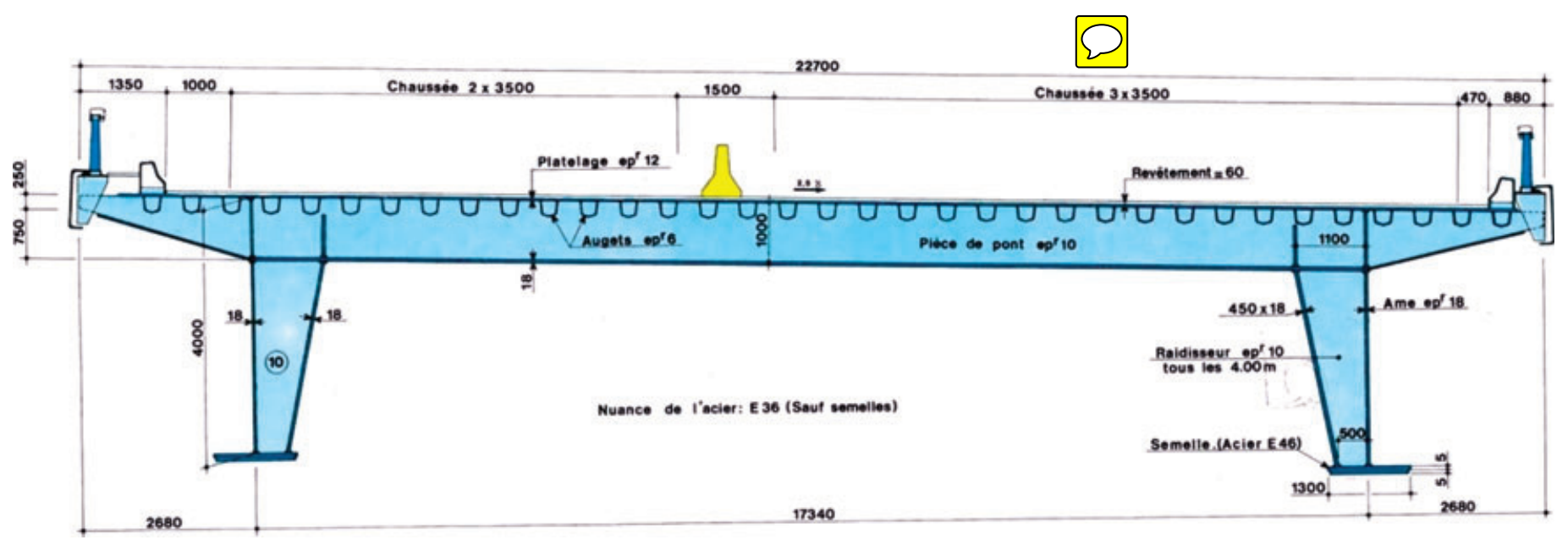

Fig. 2: Cross section of the orthotropic deck (Units: $\mathrm{mm}$ )

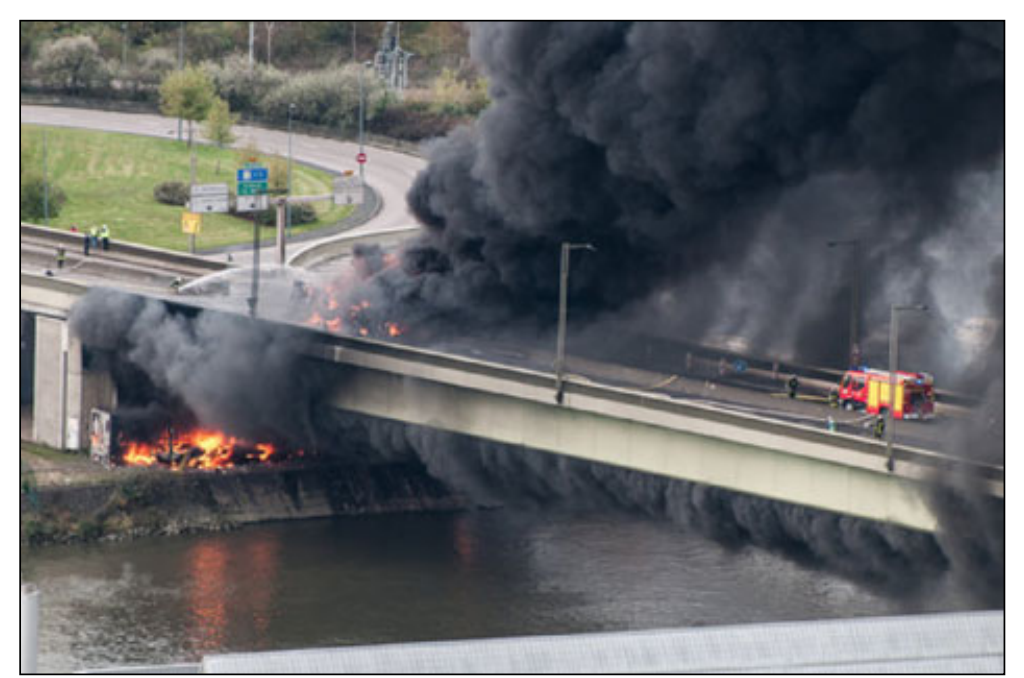

Fig. 3: General view showing the two fires, respectively, above and under the bridge (Units: \{]$\}$

diagnosis, and a crisis cell was activated by the Prefect, involving all the road managers: City, Agglomeration, Department (French local authority), State, motorway concessionaires, and the gendarmerie and police services. The Prefect also asked for the help of the State national services to provide technical assistance to the Department services; a technical committee was therefore formed comprising experts, which met in early November to pro-

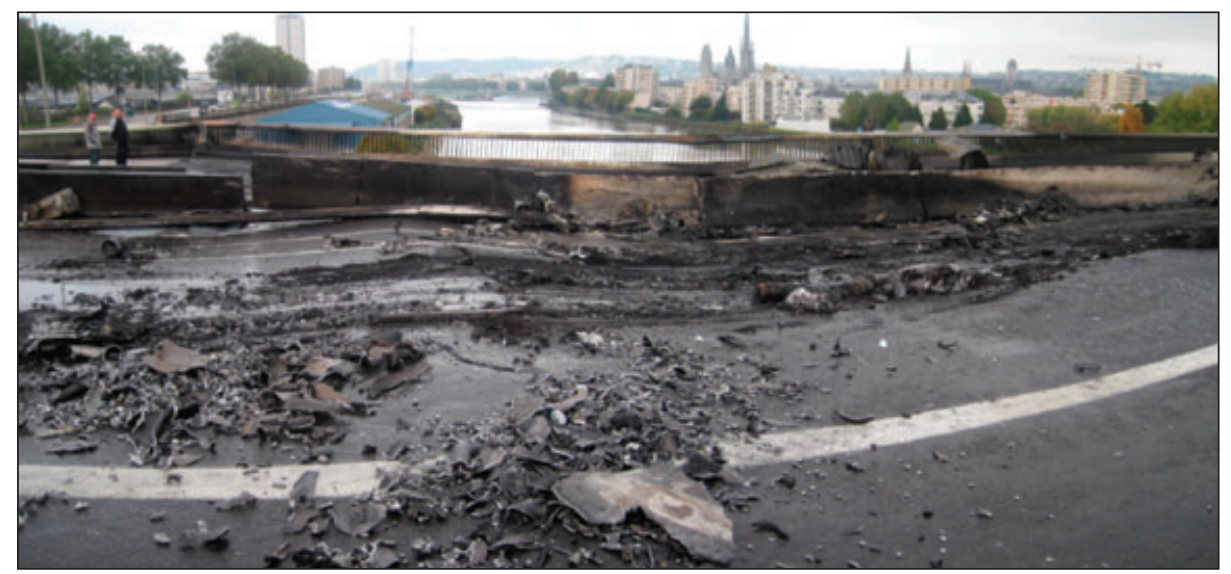

Fig. 4: Waves of the deck (Units: [ ]) vide further diagnosis and to propose

Meanwhile, the city of Rouen implemented a new traffic plan that was adjusted each day to take into account the daily requirements. The Departmental Authority opened an information website and the Agglomeration reinforced its bus transport network. The Departmental Authority regulated the movement of ferries in the west of investigations. the city with three river crossings. The Agglomeration worked on an emergency plan to restore the sewage system, and the optical fiber network was restored by temporary diversions via the Corneille Bridge located nearby.

\section{Description of the Main Disorders of the Frame}

Before describing the main disorders, it should be noted that the firefighters were able to intervene quickly with water; their action helped to limit the temperature of the steel frame before it reached the critical transition temperature of about $725^{\circ} \mathrm{C}$. If this action, which probably prevented the bridge from collapsing, had not been carried out very quickly, the effect of metallurgical quenching on steel members that had exceeded the critical temperature would have caused a steel embrittlement and then a failure of the structure.

The deck was in compression during the fire; then its thermal expansion because of the heat was hampered and restrained after the contact of the steel structure with the abutment. After the fire, it remained distorted like an accordion over a length of about 40 $\mathrm{m}$ from the south abutment (Fig. 4). The transverse beams supporting the deck were alternately raised and lowered because of the combined effect of heat, which decreases the modulus of elasticity, and, predominantly, the compression that occurred during the fire. This effect can also be observed in Fig. 5 showing the deformations of the troughs seen from underneath.

The web of the downstream girder was distorted dramatically during the fire (Fig. 6): a tensioned diagonal had formed over a length of $8 \mathrm{~m}$ from the abutment with a wave folding the first intermediate vertical stiffener located $4 \mathrm{~m}$ from the abutment. 


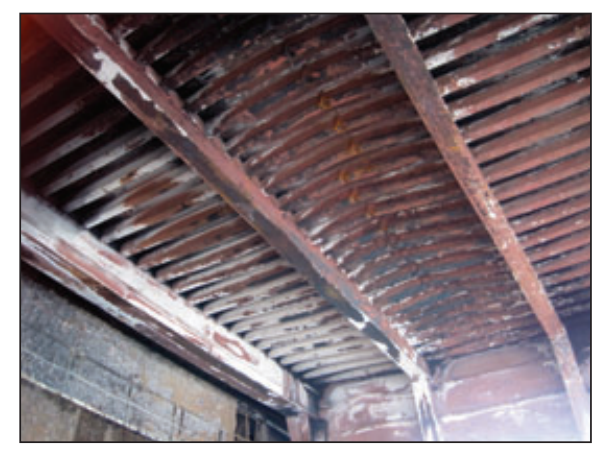

Fig. 5: Deformations of the troughs seen from underneath (Units: [ ])

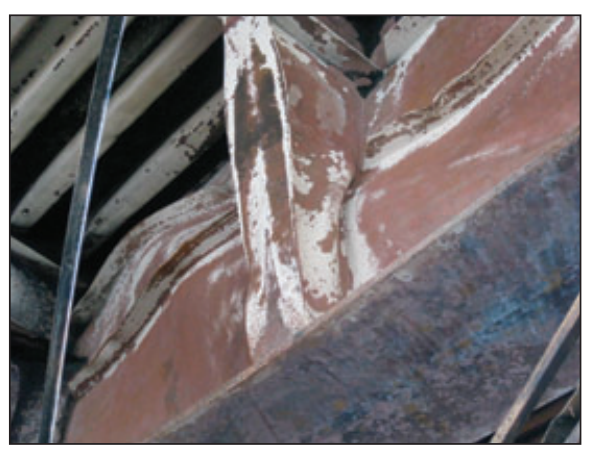

Fig. 6: Deformations of the webs of the two first panels of the downstream girder (Units: [ ])

\section{First Decisions of the Local}

Authority in Association with the Technical Committee

A Technical Committee (TC) was formed to coordinate the interventions of experts from Cerema, Ifsttar, and DRIEA. Its objective was to advise the owner of the bridge, specify the conditions for reopening the navigation on the south channel of the Seine River, assess the condition of the structure and its supports, evaluate scenarios of repair or replacement, and give an opinion on the conditions for carrying out the repair work.

Although the bridge did not collapse under its own weight, the TC recommended that no prop be installed under the span because a prop could profoundly alter the distribution of forces in the structure and, above all, it represented a serious obstacle for the navigation in the south channel. Thus, the navigation on the Seine River was restored at the end of December 2012.

The TC also recommended installing a heating system at the downstream girder end over a length of $10 \mathrm{~m}$ from the abutment. This heating was set up in December 2012 to avoid any brittle failure of the welds during the cold weather in winter. This precautionary measure was taken because the weld

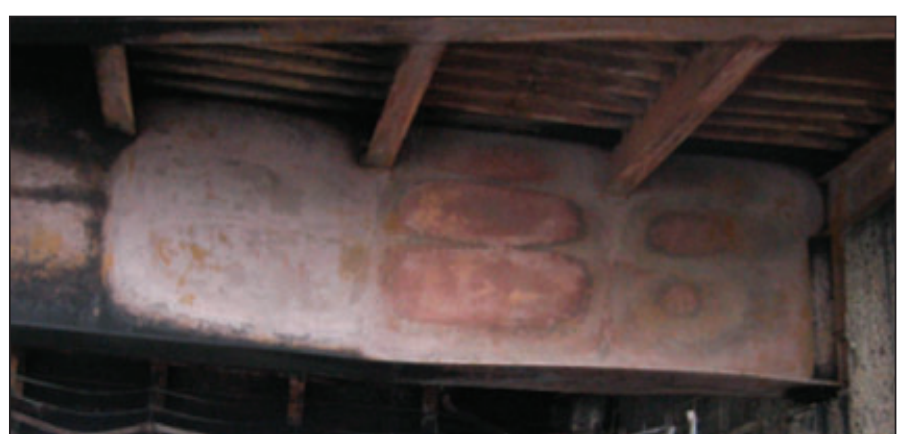

Fig. 7: Colors taken by the corrosion protection (Units: [ ]]

beads located in the deformed areas could be subjected to a steel embrittlement, and the investigation results for all the welds were not known yet. Moreover, damaged cornice elements were removed to prevent them from falling.

\section{Specific Investigations Regarding the Effects of the Heat on the Deck}

The investigations carried out on the Mathilde Bridge were derived from the emergency procedures to be published by Cerema ${ }^{4}$ to evaluate the condition of a bridge after a fire accident.

\section{Observation of Colors}

After the fire, there was every reason to suspect the presence of lead because the white color of the area was consistent with what had been observed previously in the case of the use of lead paint, for example, in the expert analysis carried out after the fire that occurred under the Bercy Bridge on the Paris ring road in December 1988.

In the case of the Mathilde Bridge, it was then possible to find the nature of the certified paint that had been reapplied 12 years ago. It was a C3 AMV 543 paint system certified by ACQPA (Association pour la Qualification et la Certification en Peinture Anticorrosion) and consisting of the following:

(1) Two layers of EP 235 (epoxy modified as primary and intermediate layers) and (2) one finishing layer of Freitane 501 (acrylic polyurethane).

This protection system contained no lead or zinc. It was a paint system that did not necessitate a removal of the entire old lead protection layer. Very often, under this type of protecting paint system, lead can be present if the project bid does not mention explicitly that the entire lead layer should be removed; indeed, the lead remaining on the bridge continues to effectively protect the steel and it does not present any risk on-site during stripping and does not endanger the health of the operators or the environment.

Samples of paint were taken later from the Mathilde Bridge and they revealed traces of lead on the girders in the area affected by the fire (up to $1 \mathrm{mg} / \mathrm{g}$ for one of the samples).

The observation of the residual deformations and color changes on the corrosion protection containing lead minium indicated that the temperature had reached at least $600^{\circ} \mathrm{C}$ in significant areas (Fig. 7). Also noticed were white lead oxides of the primer over the entire height of the web and a complete disappearance of the primer in the center of this area where the temperature had been high.

\section{Laser Topographic Survey}

The deformation of the downstream girder was measured using a three dimensional (3D) laser scanner. The laser record allowed an acquisition of 500 million points including 100 million for the end of the downstream girder. The interpretation of this survey allowed for the creation of a polygonal mesh with a precision of $\pm 1-2 \mathrm{~mm}$. The main results showed that the girder had a vertical displacement of the order of $210 \mathrm{~mm}$ and the transverse deformation of the web of the girder varied between $+160 \mathrm{~mm}$ and $-290 \mathrm{~mm}$ apart from the mean plane (Fig. 8). It can be assumed that the margins of the ultimate strength of the structure at the peak of the fire were likely very low with respect to the buckling of the downstream girder near its support on the abutment. This survey also allowed Cerema to create a mechanical model of the downstream girder end.

A survey of the twin bridge, which was not affected by the fire, was also carried out in order to measure the values of the residual deformations 


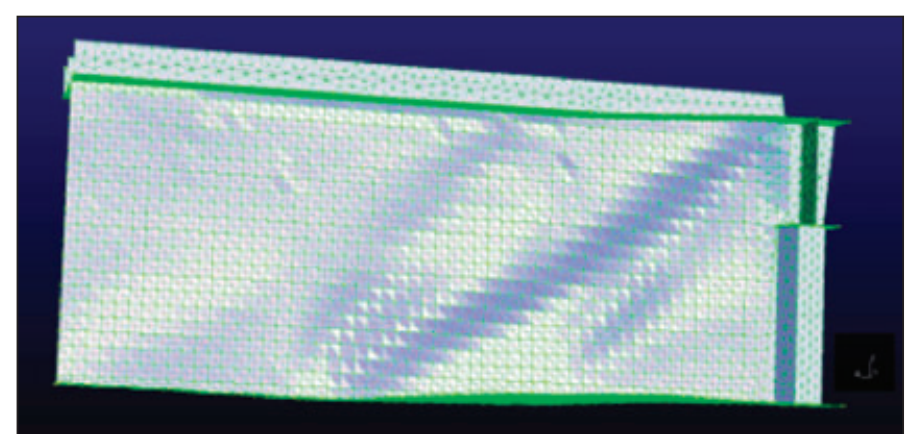

Fig. 8: Transverse deformation of the web (Units: [ ])

of the steel elements at construction. These measures helped to circumscribe the zone that had been affected by the fire as the one presenting significantly greater deformations than the deformations on the sound bridge.

\section{Examination of Fillet Welds}

A first careful visual examination of the thick weld beads on the downstream girder did not show any cracking: this observation concerned the web-vertical stiffener welds (in particular, the stiffener at the end of the girder), the web-flange welds, and the web-longitudinal stiffener welds.

This examination was then supplemented by SOCOTEC with penetrant dye tests on weld beads at the extremity of the downstream girder, on the inside, and near the tension diagonals, and with magnetic tests on different types of weld beads in areas exposed to the fire. Apart from an area that had a lot of small corrosion craters over a length of $400 \mathrm{~mm}$, and except for some spot areas at the junction of the webs and the flanges that needed to be recharged, the welds were generally in good condition.

Moreover, the tests already performed in 1998 (penetrant dye, magnetic and ultra sound waves) were reproduced on the welds of the additional flanges, according to the same procedure. No defects were detected.

It should be noted that the girders of the Mathilde Bridge are fully welded, and this configuration contributed to the survival of the bridge. For the weld beads that had not been directly subjected to the fire hoses, the high temperature of the fire may even have improved their resistance by relieving residual manufacturing stresses.

\section{Effect of Heat on Steel: Measure of the Vickers Hardness}

This measure can be easily conducted at multiple points using a portable instrument with a diamond tip. This is a nondestructive examination intended to highlight the presence of martensite, and thus to reveal embrittlement in the tempered zones that have exceeded $725^{\circ} \mathrm{C}$. The measurements were done by the Welding Institute of Le Havre. The hardness values obtained in the steel of the web and the stiffeners (ranging from 150 to 162 HV5) were quite close to that of the reference area. However, the hardness/Rm conversion applied according to the standard EN ISO $18265^{5}$ gave values of Rm that were lower or just greater than the minimum strength required for a steel grade E36-4 $(\mathrm{Rm}=510 \mathrm{MPa}$ according to the French Standard NF A35-501 ${ }^{6}$ ) and $\mathrm{E} 460(\mathrm{Rm}=590 \mathrm{MPa}$ according to the French standard NF A 36-2017). In conclusion, no evidence of embrittlement was identified by this method.

\section{Effect of Heat on Steel: Metallographic Replicas}

The replica method was implemented by the Welding Institute of Le Havre city at multiple locations on the bridge, with the help of a lightweight portable equipment, in accordance with standard NF A05-154. ${ }^{8}$. This technique allows a rapid diagnosis of the steel material after a fire and consists of five steps:

1. Local grinding to remove surface layers of oxides, paint, or decarburization

2. Preparation of the area by polishing, using extra-fine abrasive paper

3. Metallographic attack of the polished area to reveal the microstructure, by a chemical solution of nitric acid and ethanol

4. Taking the impression of the microstructure by placing a film of cellulose acetate against the steel surface

5. Microscopic examination of the films in the laboratory.

It was possible to make ten points of replicas that could be interpreted in early December 2012. Nine points

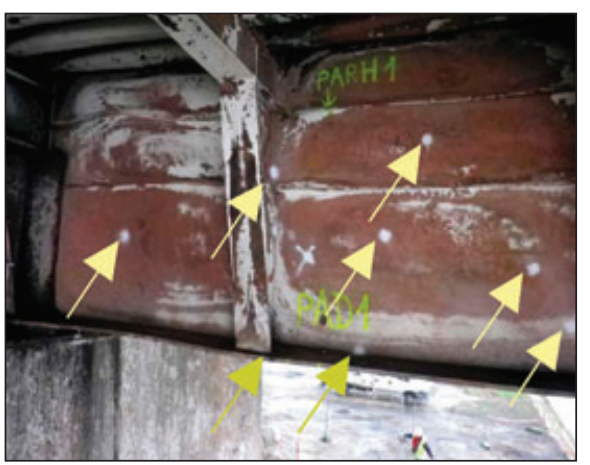

Fig. 9: Location of the replicas (Units: [ ])

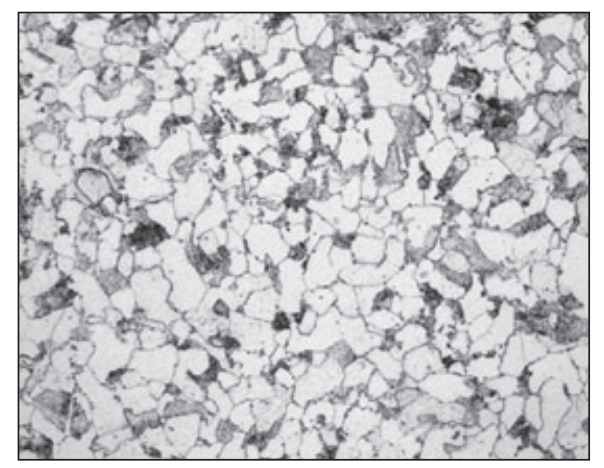

Fig. 10: Observed structure of the steel on replicas (Units: [])

were chosen on-site according to the curvatures of the steel plate and its surface appearance on the inside of the downstream girder (Fig. 9), because it was between the girders of the bridge that the warm air had been trapped and the temperature had risen the most. One of these replicas was made in the area directly sprayed by the firefighters. Some points were localized on the welds. A reference point was also taken out of the zone subjected to the fire.

The results were very positive because the observed structure of the steel (Fig. 10) was purely ferrito-pearlitic everywhere without any trace of martensite or other structures degraded by excessive heat. Moreover, the Welding Institute did not notice any (micro) cracking because of creep damage or attack by liquid metals.

\section{Effect of Heat on Steel: Steel Samples for Charpy Tests}

These samples were much smaller $\left(10 \times 10 \times 55 \mathrm{~mm}^{3}\right)$ than the samples taken for tensile tests. In addition, they provided more relevant information on the risk of embrittlement because of tempering of the steel areas that had exceeded approximately $725^{\circ} \mathrm{C}$. Therefore, many specimen were collected for Charpy tests in the highly redundant troughs of the orthotropic 


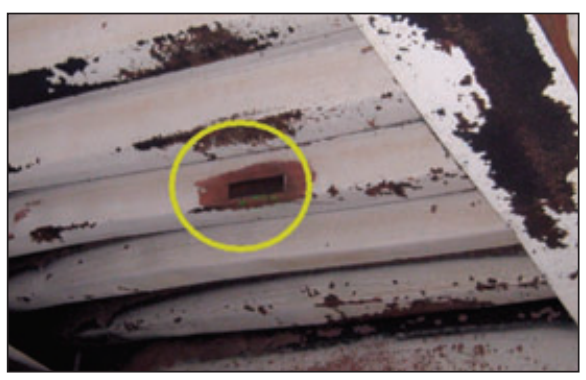

Fig. 11: Sample taken from a deck trough (Units: [ ])

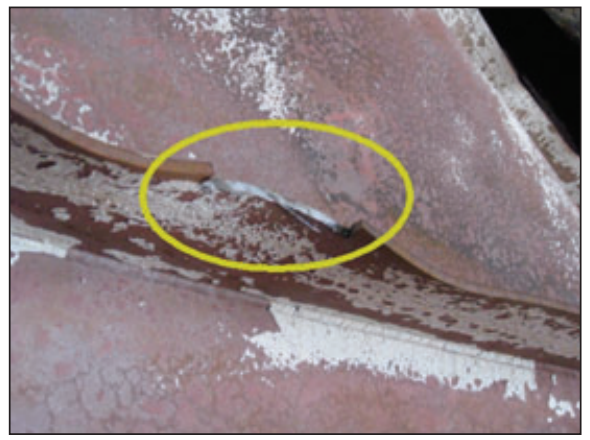

Fig. 12: Sample taken from a web stiffener (Units: [ ])

decks (Fig. 11) and at the ends of the longitudinal stiffeners of the web of the downstream girder (Fig. 12), with the objective of ensuring that these samples did not weaken the remaining structure. The samples were taken from the edge and oriented parallel to the stiffener, with a cutting a little more than $10 \mathrm{~mm}$ deep. These small samples were cut with a water-cooled saw, so that the heat from the cutting did not distort the results.

The resilience values $\mathrm{Kv}$ (at the temperature of $-20^{\circ} \mathrm{C}$ ) taken from the steel deck after the fire were between 75 and $125 \mathrm{~J}$ on the normalized specimen. They were all above the average reference value $\mathrm{Kv}$ fixed at $50 \mathrm{~J}$ and above the individual reference value fixed at $35 \mathrm{~J}$, which eliminated any risk of embrittlement and crack propagation (see in Fig. 13 the transition curve given for steel produced by Dillinger-France).

\section{Mechanical Tests on Steel Samples}

Other samples were taken by SOCOTEC and tested in tension by LHEM (Laboratoire Havrais d'Essais Mécaniques) for mechanical properties. Among 17 samples, 11 had an elastic limit Re greater than the reference value of the standard NF A 35-501, Re $=355 \mathrm{MPa}$, and six samples (all coming from the troughs) had an elastic limit less than this value. Concerning the limit strength $\mathrm{Rm}, 15$ samples had an

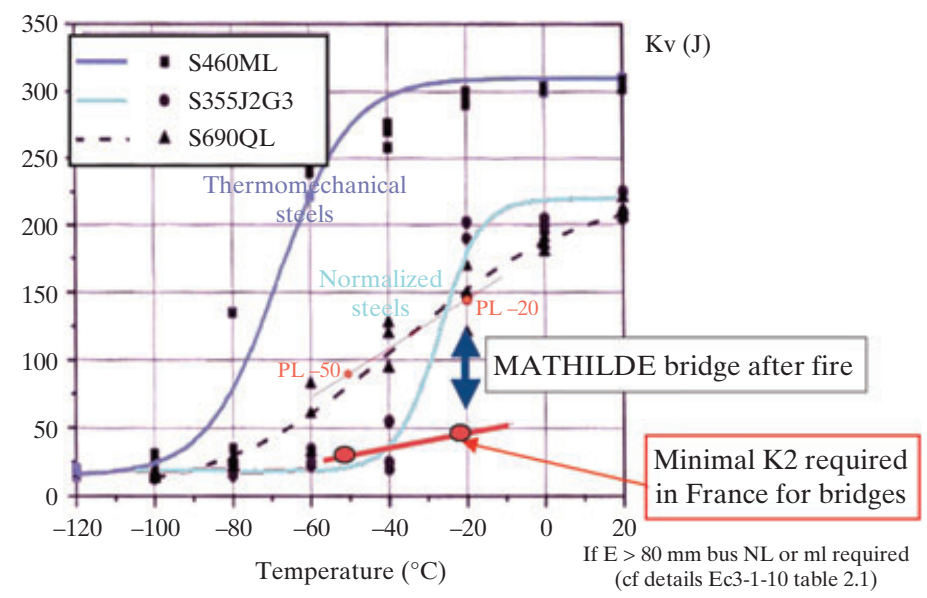

Fig. 13: Transition curves for present steel qualities $S 460$ ML and S355 J2 as comparison, for Dillinger-France products (see Ref. [9]) (Units: [ ])

$\mathrm{Rm}$ value greater than the reference value $\mathrm{Rm}=510 \mathrm{MPa}$, and two samples (from the troughs) had an $\mathrm{Rm}$ value less than $510 \mathrm{MPa}$. It was thus found that the stiffeners had a higher steel grade than that of the troughs.

The elongation values for all 17 samples were above the reference value fixed at $22 \%$ (for a plate thickness e such that $3<e<30 \mathrm{~mm}$ ). The values of the modulus of elasticity were generally satisfactory and close to $210 \mathrm{GPa}$.

\section{Chemical Analysis of the Steel}

The carbon contents of the steel measured by the Cerema laboratory of Nancy were relatively high but still below the limit value of 0.22 indicated in the French standard NF A 36-201. The carbon equivalent of the steel was between 0.423 and $0.462 \%$, which gave a high susceptibility to cold cracking. The laboratory concluded that the studies qualifying welding procedures should take this risk into account and secure precautions when welding for repair.

\section{Specific Investigations regarding the Effects of Heat on the Support Bearings}

\section{Expertise of Damaged Bearings}

The expansion joints on the abutment subjected to the fire were reopened after the fire, which seemed to show that the mobile pot bearings were functioning again. But this reopening could be attributed to the shortening of the deformed deck after cooling, and it was necessary to check it.

Even though there were no visible external damages on the pot bearings, it was impossible to evaluate the slip- ping condition of the polytetrafluoroethylene inside the pot, because a jacking necessary to remove the bearing and open the pot to observe the condition of the Teflon could endanger the stability of the structure. If the pot bearings were blocked, they could induce unexpected forces in the structure during a cold winter, and therefore it was quickly decided to record the temperature and the elongations of the two girders to check the functioning of the pot bearings, taking into account the fact that the two girders had not been exposed to the same fire. This measurement campaign was conducted by SITES over several months. Besides, a comprehensive longitudinal model of the entire bridge was developed by DRIEA (Direction Régionale et Interdépartementale de l'Equipement et de l'Aménégaement d'Ile de France, a French governmental office for roads near Paris), taking into account the thermal inertia of the prestressed concrete spans over the Lacroix Island, in order to explain the recorded measures.

Figure 14 shows a comparison of the experimental and modeled elongation of the deck, and the measured temperatures. It can be observed that the elongation of the span followed the mean temperature of the deck and that the model succeeded in explaining the observed elongation with the hypothesis of pot bearings with polytetrafluoroethylene sheets always sliding with very little friction.

The red curve is the measured air temperature. The bridge is composed of prestressed concrete parts whose thermal inertia had to be taken into account in the calculation. The green curve is the calculated temperature of the concrete parts of the bridge. 


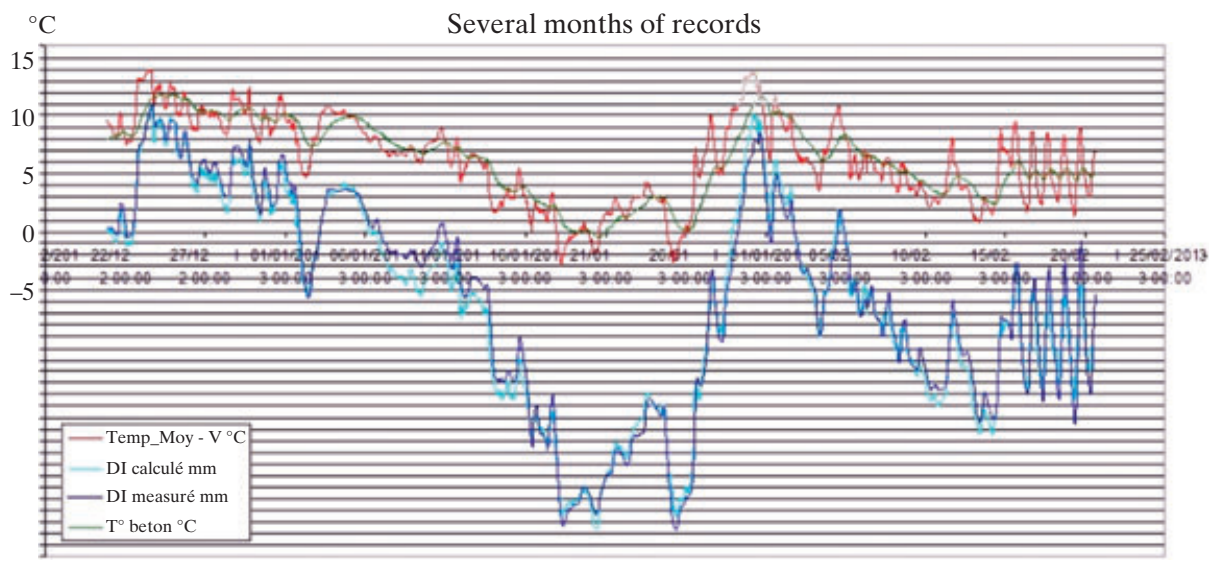

Fig. 14: Comparison of calculated and measured elongations of the deck (interval between two horizontal lines $=1 \mathrm{~mm}$ )

However, the steel parts of the bridge can be considered to be at the same temperature as the air. The central point of the concrete bridge on the Lacroix Island is supposed to be fixed. The light blue curve indicates the calculated elongations with these previous assumptions, while the measured elongations are presented in dark blue. Calculated and measured elongations were very similar over the several months of recording.

\section{Detailed Inspection of the Concrete Support}

A first examination of the south concrete abutment by the DREIA showed no visible cracking. This examination made only from accessible areas was completed later with a detailed inspection of the abutment from a positive inspection platform. The challenge was to check the resistance of the crossbeam of the abutment supporting the bearings.

A rapid sounding of the abutment face with a hammer showed no degradation of concrete at depth. It seemed that the striated architectural stamping had partially protected the structural concrete that it covered. Some aggregates were observed as having turned pink only at the surface. The removal of the deteriorated concrete, revealed aggregates that had a normal color within a depth of $10 \mathrm{~mm}$ beyond the striated architectural stamping. Some concrete scales were present, but no reinforcement steel was apparent because these scales remained within a depth of the order of a centimeter and were inferior to the cover depth. It could be concluded that the reinforcement had not been heated to a high temperature and that the resistance of the crossbeam had not been affected.
This inspection was completed by SOCOTEC taking concrete cores from the abutment wall and by carrying out a physico-chemical analysis of these cores to determine the temperature profile that had been reached. Two samples of reinforcement steel embedded in concrete were also taken and tested, the test results showed that their mechanical properties were unaffected.

\section{Recalculation of the Deformed Structure}

\section{Context of the Recalculation}

A comprehensive recalculation of the deformed girders heated by the fires would have consisted of three successive steps: the simulation of the fire scenarios, the determination of the temperature distribution in structural members, and the elastic or plastic calculation of the structural behavior during the fires. Besides the lack of time to apply this methodology, the main obstacle was the great difficulty in simulating the real fires because it was not possible to evaluate the quantity of fuel escaping through the drainage system and the gutters of the bridge, the amount of combustible materials present in the trucks parked under the bridge, and the amount of water brought by the different firefighter positions to cool the fires. In the present case, the need was to know rapidly the stress state in the deformed structure after cooling and under its own weight in order to decide if the navigation had to be interrupted on the river and if small engines could access the bridge.

\section{Elastic Calculation with the New and Very Deformed Geometry}

From the laser topographic surveys conducted by SITES, Cerema developed a mechanical model was developed for the downstream girder end. During December 2012, a first calculation was carried out with the hypotheses of an elastic material and large displacements, taking into account the second-order effects such as the membrane effect. This calculation was conducted with Code Aster STA.10, a general code of finite element analysis of EDF R \& D, which is available under GNU GPL (http://www.codeaster.org ) license. It helped to explain the good performance of the bridge under its own weight with maximum Von Mises stresses equal to $366 \mathrm{MPa}$. The deck then remains in the elastic range under its own weight $G$ (weighted by the coefficient 1.35) and considering the effect of significant residual geometric distortions caused by the fire. A horizontal concomitant effort $\mathrm{H}=300$ tons was safely considered to take account of the friction in the bearing. Figures 15 and 16 show the stresses on the extreme fibers of the most stressed shell elements. This first elastic calculation was conducted to understand the mechanical behavior of the strongly deformed structures.

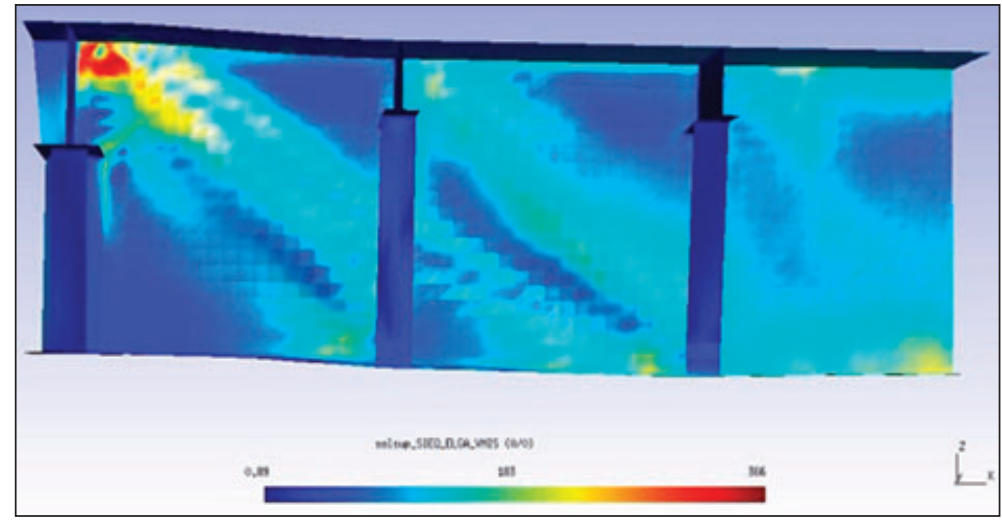

Fig. 15: Elastic calculation under $1.35 \mathrm{G}+H$ (scale ranging from 0 to $366 \mathrm{MPa}$ Units: [ ]) 


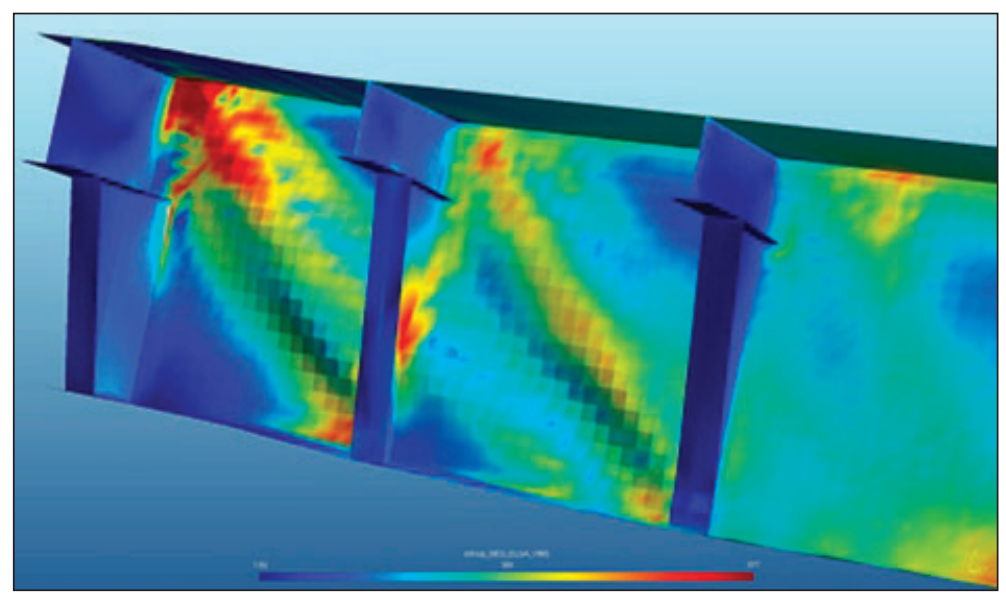

Fig. 16: Plastic calculation under 2 G (scale ranging from 0 to $377 \mathrm{MPa})$ (Units: [ ])

After all the fillet welds located in the red areas of this calculation were inspected and were found in a good condition with no observed cracks (in the red areas the stress values lay between 300 and $377 \mathrm{MPa}$, and the stresses reached the yielding stresses locally), it was decided to reopen the navigation under the bridge.

\section{Plastic Calculation with the New and Very Deformed Geometry}

The improved version of Code Aster 11.3 was then used to conduct a plastic calculation showing that the structure remained stable even under a load equal to two times its own weight (2G). The maximum Von Mises stresses reached $377 \mathrm{MPa}$ (Fig. 16). At this level of charge, the convergence of the calculation of the structure was obtained by considering both the bal- ance of efforts because of large displacements in the deformed geometry and the plastic behavior of the material. This safety reserve allowed a small engine to access the bridge for repair work, after the company had validated these results.

\section{The Decision Taken and the Repair Principle}

First, based on all the investigations conducted, it was evident that the replacement of the damaged part of the span was a minimal solution. The length of the damaged zone could be determined on the basis of a simple criterion using the second twin steel span of the bridge crossing the north arm of the Seine: a lasergrammetric record of the deformations of both the south span subjected to the heat of the fire and the twin north span, carried out by SITES. The north span helped to evaluate for each detail the fabrication tolerance that was accepted at the time of construction. It was then decided to replace the parts of the south span exceeding these tolerances.

Figure 17 shows an example of the records obtained for the end of the south downstream girder; the upper figure shows the upstream face of the end of this girder while the lower figure shows its downstream face. Similar detailed maps were scanned for the orthotropic decks of both twin steel spans. These records helped to fix the length of the span that was necessary to replace because the deformations of the orthotropic plate were so severe that it was impossible to repair the plate. It was therefore decided to replace about $40 \mathrm{~m}$ of the $105 \mathrm{~m}$ long span.

After it had been decided to replace the damaged part of the deck, several solutions were studied to repair the bridge:

- One solution was to use provisional reinforcements of the damaged bridge with props in the Seine River: this option would have changed the static functioning schema of the bridge, in particular where the lower flange was made of two plates welded together, that were in tension rather than in compression. This solution could have allowed the provisional restoration of the
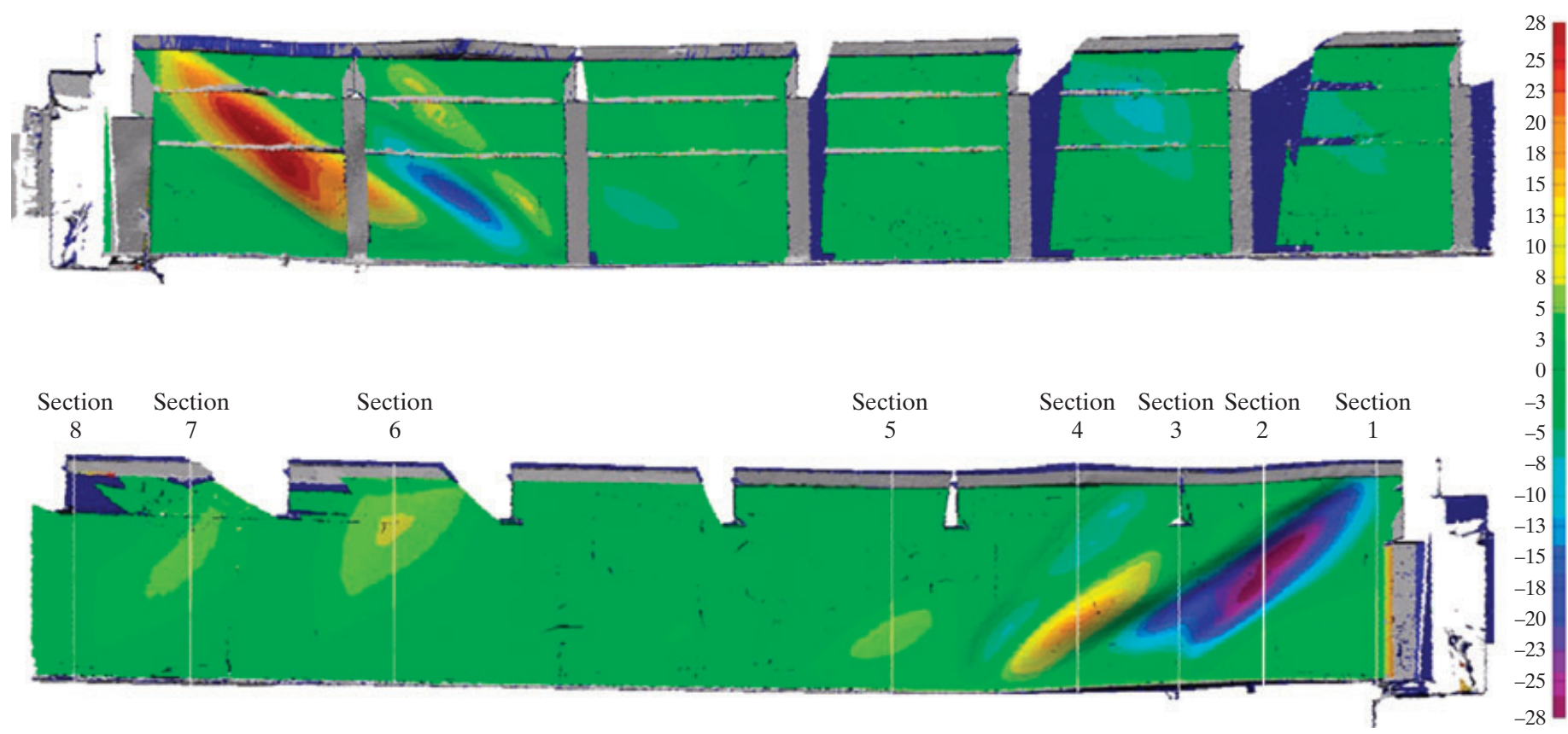

Fig. 17: SITES lasergrammetric records on a scale between -280 and $+280 \mathrm{~mm}$ (upstream and downstream faces of the damaged end of the downstream girder) (Units: [ ]) 
road traffic on the bridge for two or three months during the fabrication of a new span. However, this option would have meant a huge restriction on ship movements with economic consequences because the passage by the northern arm is more difficult than by the southern arm. In addition, the partial replacement of the span on-site would have been very difficult, particularly because the old burned paint would have to be removed in the city center of Rouen and over the Seine River, which would mean drastic restraints on working conditions, for both the health of the workers and the protection of the environment.

- A second solution was the full replacement of the span; it would have caused longer delays in the reopening of the bridge and additional costs in comparison with a partial replacement.

- A third solution was the replacement of only the damaged 40 $\mathrm{m}$ long zone of the span and its transportation to a berth $10 \mathrm{~km}$ away from Rouen in the city of Petit-Couronne. This solution was the most economical and also the least disturbing for the navigation, and was therefore chosen by the authorities that submitted a tender for the repair.

It was also decided to respect the initial design and geometry of the bridge because the geometry of the existing orthotropic deck is not very different from the geometry proposed today in the Eurocodes. However, an orthotropic deck respecting all the specifications of the Eurocode $3^{10}$ would have been heavier and would, therefore, have necessitated a strengthening of the prestressed concrete parts of the bridge with additional tendons. Moreover, this additional cost would probably not be refunded by the insurances covering the risks of such a fire accident. In addition, the application of the Eurocodes to only a part of the span without changing the rest of it made little sense.

\section{The Repair of the Span}

The choice of replacing in an identical way the damaged part of the bridge avoided new studies and saved time. The steel could be ordered immediately from the steel industry. The fabrication of the new pieces of the bridge began very early while the whole of the old span was transported to the berth at Petit-Couronne. Furthermore, the removal of the bridge through the waterway offered many technical advantages. As the bridge was transported to a dock distant from the site, only damaged parts were cut and replaced with new parts.

This transportation principle of the entire span had already been chosen in 1979 for the construction of the bridge. It had several advantages, which were verified during the repair works:

- There was very little interference to navigation except during the 2 days that were necessary for the removal and the reinstallation of the entire span.

- It carried less risk than a prop that deeply modified the mechanical functioning of the bridge in the interim phase.

- A simple solution was found by Cerema to avoid any strengthening of the supporting prestressed concrete cantilever span by additional tendons: it consisted of installing a ballast and this latter was made with the waste from the deconstruction of the pavement of the steel span.

- It provided hazard reduction with regard to repair works because a better quality of execution could be achieved on the berth by avoiding the constraints resulting from work over the Seine River. The span could be carefully inspected on the berth. A very small number of fatigue cracks were found in the fillet welds assembling the longitudinal U-shape troughs to the deck plate at the location of the passage of the truck wheels. It was also easy to replace the areas where cracks were discovered, and this could not have been possible when working on props in the Seine River.

- There was no inconvenience to the public at the bridge site in the city, especially during the renovation of the corrosion protection. The paint stripping in the city over the Seine River would have required the installation of a scaffold, engaging the navigation clearance, and a containment to ensure both safety conditions and environmental protection. The additional risks created by the potential presence of lead on the bridge was also a reason for preferring to transport the whole span to a berth near Rouen; however, contrary to what had been suspected, no lead was found on the part of the bridge that was reused and repainted.

\section{Conclusions}

Although this article is devoted to the benefits offered by all existing investigation techniques in helping to assess and manage a steel bridge affected by a fire in order to find an optimized repair solution, the present conclusions are focused on the various consequences of the closing of a bridge supporting heavy traffic in a populated area. The implementation of a plan to bypass transit flows via A29 Motorway and the Normandy Bridge significantly reduced the transit traffic. On some secondary roads, particularly in the east of the city, the heavyweight traffic had doubled, resulting in a significant deterioration of pavements. It was the same to the west with an increase in traffic in urban areas through the Cailly valley (the city of Maromme, in particular).

Moreover, this situation, with essentially only one bridge (Flaubert Bridge with $2 \times 3$ lanes) to support the North-South traffic through the Rouen City, caused problems every day. Indeed, when an accident occurred at the approach of this bridge, the whole agglomeration became congested very quickly. On some days (exceptional circumstances), it took almost $2 \mathrm{~h}$ for transit vehicles to cross the Seine River. It has been established that on some days, there were more than $60 \mathrm{~km}$ of traffic jams. The traffic crossing over the Seine River decreased by 40000 vehicles per day.

The use of public transport such as trains, intercity (about 10\%) and urban (more than $15 \%$, especially on own site lines), has increased. Bicycle use has also increased despite the rugged topography and the hazardous roads for practice. Walking has made its comeback for travel over short distances. A survey conducted during the spring of 2013 by the Chamber for Trade and Industry shows that about $10 \%$ of economic actors have seen their situation weaken because of accessibility issues.

Today several companies or establishments involved in the disaster are going to court to obtain compensation for their harm. The local Authority of SeineMaritime, despite pending judicial decision regarding fixing the amount of damages to the bridge, undertook its rehabilitation. However, transporting the damaged span to a berth turned out to be an excellent method for the 
repair work and it is certain that it will be used again in Rouen, if necessary, for the maintenance of steel bridges. The bridge was reopened to traffic on 26 August 2014, exactly on the scheduled date.

\section{Acknowledgment}

The authors thank the following companies and institutions for having provided the results of their investigations: SITES, SOCOTEC, Laboratoire Havrais d'Essais Mécaniques, Laboratory of Cerema at Nancy, Direction Régionale et Interdépartementale de l'Equipement et de l'Aménagement d'Ile de France.

\section{References}

[1] Roche J. Le Pont Mathilde à Rouen: les etudes. Bulletin Ponts Métalliques no. 7, Office Technique pour l'Utilisation de l'Acier, Juillet, 1980, 51-55.

[2] De la Codre E. Le Pont Mathilde à Rouen: l'exécution et le montage. Bulletin Ponts Métalliques no. 7, Office Technique pour l'Utilisation de l'Acier Juillet, 1980, 57-58.

[3] Eisel H, Palm N, Prehn W, Sedlacek G. Brandschaden und Instandsetzung der WiehltalBrücke im Zuge der A4, Köln - Olpe. Stahlbau 2007; 76: Heft 2.

[4] Cerema: Résistance à l'incendie - Évaluation des ponts routiers. Technical Guide, 2015 (to be published) (in French).
[5] AFNOR: NF EN ISO 18265. Metallic materials - conversion of hardness values, 2004.

[6] AFNOR: NF A35-501. Aciers de construction d'usage général. Nuances et qualités. Tôles minces, moyennes et fortes, larges plats, laminés marchands et poutrelles, 1973 .

[7] AFNOR: NF A 36-201. Produits sidérurgiques. Tôles en aciers soudables à haute limite d'élasticité. Nuances et qualités, 1975.

[8] AFNOR: NF A05-154. Produits en acier Techniques de réplique métallographique (examen optique), 1985.

[9] AFGC.Les aciers à Haute Limite d'Elasticité Documents Scientifiques et Techniques, 2012, 256 p. (in French).

[10] CEN: EN 1993-2. Design of steel structures - Part 2: Steel bridges, 2006. 